\title{
Contemporary and future perspectives for hydrological and catchment sciences
}

Catchments have provided the focal point for much hydrological, hydrogeochemical and environmental science over the past fifty years. Experimental catchment research provides an important base for understanding how the environment functions both in relation to 'natural' and 'maninduced' processes. The papers in this volume set out many of the developments in water sciences that have occurred since the Symposium entitled $A$ View from the Watershed held at the Institute of Hydrology (IH) in 1973. Many of the papers describe developments that have stemmed from catchment research to which many people have contributed, including members, past and present, of the Institute of Hydrology (now the Centre for Ecology and Hydrology), and many associates around the world. The papers pay tribute to the outstanding contribution of Dr Jim McCulloch, not only as IH's first Director, but also subsequently as Editor of the Journal of Hydrology and of Hydrology and Earth System Sciences (HESS).

These developments have in part been stimulated by major improvements in electronics, computing, satellites and other technologies, which have greatly facilitated the recording and transmission of field measurements, the quality control of data, the development of databases, the ease with which data are transmitted across the world, the chemical analysis of samples in the laboratory, and the integration of data on water fluxes and chemistry into descriptions of catchment and vegetation behaviour. To perhaps a greater extent, they have also been stimulated by the growing awareness of the importance of water as an essential resource, of the importance of freshwater environments to the well-being of communities, and of the economic damage inflicted by floods, droughts and careless land-use, urban and industrial change. They have also been stimulated in substantial measure by management with sufficient vision to see beyond the short-term, capable of discerning that changes in land use and pollutant climate require long-term studies extending over one or more cropping cycles. All three factors technical development, awareness of the importance of the water resource, and long-term vision in water research have contributed to the science reviewed in this volume. Research which originally focussed on the hydrology of river basins now extends to hydrogeochemistry and is being extended further into freshwater biology and the function of ecosystems. Catchment science now extends beyond the small plot and the headwater stream to the level of the riverbasin and region, and from pristine and rural environments to the industrial and urban. The nature of catchment science is changing as the combination of disciplines needed and range of environments worthy of study increase. The need for integrated catchment research has never been greater. As the contributions in this special issue illustrate, catchment science is lively, extensive and forward looking.

If we look forward to a third symposium in the series, to be held perhaps in 2030, what might be the issues discussed in its research contributions? It is of course dangerous to make predictions but we may speculate that, whilst the research of the last quarter-century has concentrated to a large extent on what happens to water and its chemistry on reaching the ground - 'looking downwards', as it were the research of the coming quarter-century will also be concerned, to a greater extent than hitherto, with 'looking upwards': with a move towards assessing the causative mechanisms that influence precipitation distribution in space and time, with the relationships between atmospheric and oceanic processes, and with modelling these relationships in mathematical terms to predict climate fluctuations and their consequences and the impacts of humans on the environment. The trend towards widening the physical and chemical aspects of catchment science to include biological, ecological and even economic and social dimensions may continue, bringing with it the difficulties and limitations of holistic treatment of complex systems.

Whatever the science that is reported at the next symposium, we may be sure that the research of the last half-century, to which Jim McCulloch has contributed so greatly, will provide its solid foundation.

We, the Guest Editors, close this volume with a positive message for catchment science. But the future for catchment science requires more than ideas and good intentions; it also needs the sustained funding and enlightened administration which allowed the Institute of Hydrology to develop so successfully.

Colin Neal and Robin Clarke 